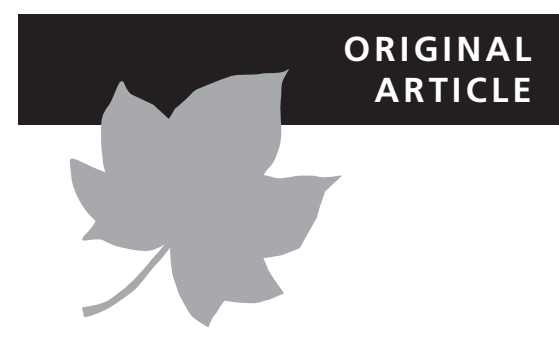

\title{
Disentangling the influence of climatic and geological changes on species radiations
}

\author{
H. Peter Linder ${ }^{1 \star}$, Daniel L. Rabosky ${ }^{2}$, Alexandre Antonelli ${ }^{3}$, \\ Rafael O. Wüest ${ }^{1,4}$ and Ralf Ohlemüller ${ }^{5}$
}

${ }^{1}$ Institute of Systematic Botany, University of Zurich, Zurich CH 8008, Switzerland, ${ }^{2}$ Department of Ecology and Evolutionary Biology, Museum of Zoology, University of Michigan, Ann Arbor, MI 48109-1079, USA, ${ }^{3}$ Department of Biological and Environmental Sciences, University of Gothenburg and Gothenburg Botanical Garden, Göteborg, Sweden, ${ }^{4}$ Landscape Dynamics, Swiss Federal Research Institute WSL, Birmensdorf CH 8903, Switzerland, ${ }^{5}$ Geography Department, University of Otago, Dunedin, New Zealand

${ }^{*}$ Correspondence: H. Peter Linder, Institute of Systematic Botany, University of Zurich, Zollikerstrasse 107, Zurich CH-8008, Switzerland.

E-mail: peter.linder@systbot.uzh.ch

\section{ABSTRACT}

Aim Our aim was to seek explanations for the differences in the diversity among the austral continents by comparing the diversification rates and patterns in the grass subfamily Danthonioideae. We asked specifically whether diversification is density dependent, whether it is different for each continent, and whether immigration rates impact on diversification rates. We attempted to account for intercontinental differences by comparing the Pleistocene climatic and Neogene geomorphological histories with the inferred diversification rates.

Location Mainly the Southern Hemisphere, treated as four areas for the analyses: Africa, Australia, New Zealand and South America.

Methods We based our analyses on a densely sampled, dated phylogeny for the grass subfamily Danthonioideae. We compared 24 diversification models for these continental radiations, taking into account speciation models, and extinction and dispersal rates. We used available distribution data to infer the climates under which danthonioids are found, and used these to estimate the change in area and location of suitable habitats between contemporary and Last Glacial Maximum climates. We inferred the geomorphological history from the literature.

Results We show that long-distance dispersal led to parallel radiations, which more than doubled the final standing diversity in the subfamily. Diversification models with the strongest support included separate time-varying diversification processes for each major geographical region. Pleistocene climatic fluctuation did not explain the intercontinental differences in diversification patterns.

Main conclusions Although our results are consistent with density-dependent diversification, this explanation is not consistent with the time of arrival of danthonioids on each continent. The diversification patterns on the four major Southern Hemisphere landmasses are idiosyncratic. The two most important predictors of diversity may be the lineage-specific effect of time, and the general effect of topographical complexity and orogenesis.

\section{Keywords}

Danthonioideae, dispersal, diversification rates, extinction, geomorphology, Last Glacial Maximum, orogeny, Poaceae, speciation.

\section{INTRODUCTION}

Although danthonioid grasses (Danthonioideae, Poaceae) (Linder \& Barker, 2000; Linder et al., 2010) are common and often dominant elements in the temperate $\mathrm{C}_{3}$ grasslands

(c) 2014 John Wiley \& Sons Ltd of the southern continents, species richness varies markedly among continents (Fig. 1). Spatial variation in species richness among the austral continents is well known (Kier et al., 2009), especially for the mediterranean climate regions (Cowling et al., 1996), but because of the almost complete 




Figure 1 Distribution of the Danthonioideae. Each area is colour coded, and the genera and numbers of species listed. Note that several genera are found in more than one area.

absence of clade-based comparative analyses of diversification patterns across the southern continents (but see Linder et al., 2003), we have no explanations for this variation.

Spatial variation in species richness may be the result of key innovations, differences in time available for diversification, immigration rates or ecological opportunity. Key innovations (Hodges \& Arnold, 1995) are obviously important, but can be discounted in the danthonioids as a result of repeated dispersals across the southern oceans (Linder et al., 2013). Both palaeontological (Sepkoski, 1978; Alroy, 2008) and molecular phylogenetic (Phillimore \& Price, 2008; Rabosky \& Lovette, 2008a; Etienne et al., 2012) studies have suggested a prominent role for diversity-dependence in mediating the tempo of species diversification, suggesting that carrying capacity rather than time available might regulate diversification rate. If, however, there are no slowdowns in the diversification rates, then diversification is primarily limited by evolutionary time within regions, consistent with an expansionist model of diversification, as suggested by Wiens and collaborators (Wiens et al., 2006, 2009). The effect of immigration rates on diversification appears not to have been fully explored. The dispersal of a lineage to a new area can trigger a radiation in this area, as has been demonstrated for numerous clades in Hawaii (Baldwin \& Wagner, 2010), New Zealand (Winkworth et al., 2005) and the Mascarenes (Juan et al., 2000), as well as for particular taxa such as Brassicaceae (Karl \& Koch, 2013). However, dispersal into an area already occupied can, by the addition of new genetic diversity, stimulate further diversification (Wagner et al., 2012). In contrast to migration, ecological opportunity has been a popular explanation of diversification, and can result from one of three types of abiotic events. First, regional climate change can create locally new opportunities, for example the development of summer drought resulting from the acceleration of upwelling of Antarctic bottom waters on the southern African west coast, triggering the radiation of the Cape flora in southern Africa (Linder, 2003; Verboom et al., 2009; Dupont et al., 2011). Second, orogeny might create new habitats and opportunities, which has been argued for the Andes (Antonelli et al., 2009) and New Zealand (Winkworth et al., 2005). Third, long-distance dispersal to islands such as Hawaii (Wagner \& Funk, 1995; Givnish et al., 2009), to mountain regions on continents (Hughes \& Eastwood, 2006), and into floras on different continents such as the African Cape flora (Galley \& Linder, 2006), might expose a lineage to new environments and climates. Biotic modifiers (Linder et al., 2012) can also change environments, and provide the context for new radiations. The three abiotic variables are often tightly interwoven, as orogeny may alter the climate and create new environments into which lineages can disperse and radiate. This is exemplified by the lupin radiations in the Andes resulting from dispersal from North America to the new alpine climate generated by the Late Miocene Andean orogeny (Hughes \& Eastwood, 2006). Climate change may also influence extinction rates (Crisp \& Cook, 2009), and mountains may ameliorate the effects of 
climate change (Loarie et al., 2008; Lancaster \& Kay, 2013) by providing a rich diversity of locally available habitats. However, orogeny could also drive climate change, for example by blocking the flow of moist air.

Here we attempt to disentangle the effects of time, dispersal, climate change, topography and orogeny on diversification rates in the danthonioid grasses. We use a modelbased approach to test whether diversification rates are continent-specific, whether there is evidence for a diversitydependent pattern, and whether immigration rates influence the diversification rates. We evaluate the possible impact of past climate change on each continent by comparing differences between the modelled distribution ranges for Last Glacial Maximum climates with contemporary climates, to differences in diversification rates. Finally, we ask whether intercontinental diversification rate differences might be accounted for by differences in the histories of orogenesis.

\section{MATERIALS AND METHODS}

\section{Phylogeny}

In order to compare the radiations on the different continents we used an almost completely sampled, time-calibrated phylogeny of the Danthonioideae (Antonelli et al., 2011; Linder et al., 2013), which comprises 299 accessions and 14,425 characters. Multiple accessions of species that are not demonstrably polyphyletic were reduced to a single accession (17 of 27 duplicated taxa were thus pruned). Species in which multiple accessions had disparate positions based on cpDNA only were retained for Pentameris pallida (Thunb.) Galley \& H.P.Linder and Rytidosperma caespitosum (Gaudich.) Connor \& Edgar. This resulted in a set of 1000 randomly sampled post-burn-in phylograms, with 274 accessions representing 252 taxa (species and subspecies, constituting $81 \%$ of the danthonioid species), and with widespread species represented by multiple accessions, and including six outgroup taxa. This set of trees was rate corrected and calibrated as described in Linder et al. (2013), using BEAST 1.5.2 (Drummond et al., 2006). The matrix and trees are available on request from the first author.

\section{Continental diversification patterns}

In order to identify major processes that have shaped danthonioid diversity across the larger continental landmasses of the Southern Hemisphere (South America, Africa, New Zealand, Australia), we used character-state-dependent models of speciation and extinction (Maddison et al., 2007; FitzJohn et al., 2009; Rabosky \& Glor, 2010). This class of models has been used previously to study the geographical context of species diversification (Rabosky \& Glor, 2010; Goldberg et al., 2011) and accounts for some biases in the inference of ancestral geographical states caused by regional differences in rates of species diversification. We considered a set of models that would potentially enable us to assess whether patterns of lineage accumulation in extant danthonioids are dominated by (1) intrinsic, clade-specific rates of species formation, (2) regional differences in factors that promote speciation, and (3) diversity-dependent regulation of species richness.

The general theory underlying dynamic, character statedependent models of speciation and extinction as applied to molecular phylogenies has been described elsewhere (Maddison et al., 2007; Rabosky \& Glor, 2010). We used maximum likelihood to fit four general classes of diversification (speciation, extinction) models to the time-calibrated danthonioid phylogeny. We refer to the simplest model as 'GlobalConstant': this model assumes simply that rates of species diversification have been constant through time, and that all geographical regions share common diversification parameters. The second model class, 'RegionalConstant', assumes that diversification rates have been constant through time, but that these rates vary among continental regions. The third model class, 'RegionalDynamic', assumes that diversification rates have varied through time within geographical regions. We assumed a simple linear change in evolutionary rates through time, bounded at zero, such that the rate of speciation $(\lambda)$ at any point in time $t$ was modelled as:

$$
\lambda(t)=\max \left\{0, \lambda_{0}(1-t / z)\right\},
$$

where $\lambda_{0}$ is the initial rate of speciation at the root of the tree, and $z$ is a parameter that controls the rate of change in $\lambda$ with respect to time. Finally, we constructed a 'GlobalDynamic' model, such that species diversification rates varied linearly through time, but with all regions sharing common rate parameters.

It is theoretically possible to estimate extinction rates from molecular phylogenies (Nee et al., 1994), but recent studies have suggested that empirical estimates of this parameter may be problematic (Rabosky, 2009a, 2010; Quental \& Marshall, 2011). We thus formulated two versions of each model described above: one where the extinction rate $(\mu)$ was constrained to be equal to zero, and another where extinction rates were free to vary. In each case, the extinction model was assumed to be a mirror image of the corresponding speciation model. Thus, for the RegionalDynamic model with $\mu \geq 0$, we assumed linear time-dependent variation in extinction rates, bounded at $\mu=0$. This model explicitly allowed extinction rates to exceed speciation rates, and it was even possible for extinction rates to increase while speciation rates decreased through time for the dynamic (linear) models. Each geographical region in the RegionalDynamic model with $\mu \geq 0$ thus included two speciation parameters and two extinction parameters.

Each of the models described above corresponds to one or several processes that may influence the tempo of lineage accumulation in the danthoniods. The GlobalConstant model is expected to fit the data best if the tempo of lineage accumulation is similar across all geographical regions and if there are no strong abiotic controls on species richness (Rabosky, 2009b). Such a model might be preferred if the rate of speciation is limited by the rate at which lineages accumulate 
intrinsic reproductive isolation. If species richness is governed by diversity-dependent regulation of speciation and/or extinction we predict that all geographical regions should show evidence for declining rates of speciation through time (Phillimore \& Price, 2008; Rabosky \& Lovette, 2008b; Etienne et al., 2012), as has been shown for Anolis lizards on the Greater Antilles (Rabosky \& Glor, 2010). Regional differences in the rate of diversification, especially if some are increases and others decreases in the diversification rate, should lead to superior fit of either the RegionalDynamic or RegionalConstant models. Superior fit of the GlobalDynamic model may suggest that a common global factor is mediating common trends in lineage diversification despite the physical separation between the four focal regions.

We fitted each of the diversification models above against three biogeographical 'background' models (Rabosky \& Glor, 2010): a model with equal rates of dispersal among geographical regions ('OneRate'; one parameter); a model where the dispersal rate between regions varied linearly through time, as for speciation and extinction ('TimeDependent'; two parameters); and a model with symmetric, time-invariant dispersal rates between each pair of geographical regions ('Symmetric'; six parameters). We did not include a timeconstant asymmetrical model, typical of biogeographical approaches such as the dispersal-extinction-cladogenesis (DEC) model implemented in Lagrange (Ree \& Smith, 2008), because of concerns over the large number of model parameters in comparison to the relatively small number of transitions between geographical regions. All analyses were performed on pruned phylogenetic trees for the danthonioids that included only those taxa found in the four southern continental regions: southern/central Africa $(n=122)$; New Zealand $(n=39)$; Australia $(n=42)$; and South America $(n=38)$. Only three species are found in more than one area: all three are shared between New Zealand and Australia, and belong to the genus Rytidosperma. These regions are largely congruent with the areas of endemism defined by Linder et al. (2013), except for East and southern Africa, which were combined owing to the small number of species in East Africa. Because few species occurred in the regions we excluded from the analysis (e.g. New Guinea, $n=11$; North America, $n=8$; Madagascar, $n=6$; Europe, $n=4$ ), we could not justify the significant increase in model complexity associated with additional region-specific parameters, despite this reducing our 'sample size' of intercontinental comparisons. Early attempts to include regions with few taxa failed to converge on stable parameter estimates. As there is no evidence of dispersal from these excluded areas to our four continental areas (Linder et al., 2013), excluding them should not affect our results. We accounted for unsampled taxa within each region analytically in our likelihood calculations after FitzJohn et al. (2009).

Our full analysis thus considered a total of 24 possible models: four core diversification models were each evaluated with and without extinction, and against three background geographical dispersal scenarios. The models ranged in complexity from a simple GlobalConstant model $(\mu=0)$ with a single dispersal parameter (two parameters in total) to the RegionalDynamic model $(\mu \geq 0)$ with symmetric dispersal (22 parameters in total). All models were fitted using code that we developed for the $\mathrm{R}$ statistical platform; differential equations for the dynamics of speciation and extinction probabilities were coded in $\mathrm{C}$ and solved numerically using the LSODA routine as implemented in the DeSolve library for $\mathrm{R}$ (Soetaert et al., 2011). Source code for fitting these models is available upon request. Owing to the large number of parameters in some of the models, we maximized the likelihood for each model using at least 800 sets of random starting parameters. Fitting the more parameter-rich models was computationally intensive and in some cases required more than 20,000 likelihood evaluations for each optimization. To assess whether our results were robust to phylogenetic uncertainty, we repeated our analyses on 500 phylogenies from the posterior distribution of trees. We compared models by computing finite-sample corrected Akaike information criterion $\left(\mathrm{AIC}_{\mathrm{c}}\right)$ scores and Akaike weights for each model. Akaike weights can be interpreted as the conditional probability of a particular model given the candidate set of models investigated. The $\mathrm{AIC}_{\mathrm{c}}$ has a modified penalty term that reduces overfitting with finite sample sizes relative to the standard AIC. As a heuristic tool for visualizing lineage accumulation dynamics, we reconstructed lineage-through-time plots for geographical regions and across the full global radiation for the posterior sample of phylogenies. We estimated the number of lineages within each geographical region as the sum of marginal probabilities associated with each region at each point in time, as described in Mahler et al. (2010).

\section{Available climate space}

To test whether fluctuations in the available habitat during the Quaternary influenced diversification rates, and particularly extinction rates, we identified the geographical distribution of areas climatically suitable for danthonioids for the contemporary climate (1961-1990) and the Last Glacial Maximum (LGM, $21 \mathrm{ka}$ ). The contemporary climate approximates the most mesic phases of the Quaternary, and the LGM can be taken to approximate the coldest periods of the Pleistocene (Pahnke et al., 2003; Li et al., 2011), consequently the differences between current and LGM climates have been used as measure of the magnitude of Quaternary fluctuations (Sandel et al., 2011). We characterized the multivariate climatic conditions suitable for danthonioid species (the danthonioid climate space) based on the current distribution of 29,317 georeferenced herbarium specimens assembled from herbaria in Africa, Australia, New Zealand and South America and the current climatic conditions at these locations. Analyses were performed on a global $2.5^{\prime} \times 2.5^{\prime}$ grid (c. $4.6 \mathrm{~km} \times 3.3 \mathrm{~km}$ at $45^{\circ} \mathrm{S}$ ), which might constitute the optimal balance between cells that are too heterogeneous 
(especially for the mountainous habitats in southern Africa, New Zealand and South America), and a very unwieldy and spuriously accurate dataset. For each grid cell, six climate variables from WorldClim (Hijmans et al., 2005) were used for the two time periods: mean annual temperature (BIO1), mean temperature of the warmest quarter (BIO10), mean temperature of the coldest quarter (BIO11), annual precipitation (BIO12), precipitation of the warmest quarter (BIO18), and precipitation of the coldest quarter (BIO19). These were selected in order to give a robust general characterization of both annual average and seasonal climatic conditions. We calculated the true area of each grid cell using great circle distances and then quantified for each region the area with danthonioid-analogous climate niche conditions under current and under LGM climate conditions. We used two LGM climate models: the Model for Interdisciplinary Research on Climate MIROC3.2 (http://www-pcmdi.llnl.gov/ipcc/ model_documentation/MIROC3.2_medres.htm) and the Community Climate System Model CCSM3 (http://www. cesm.ucar.edu/models/ccsm3.0/\#docs).
For each of the four regions, we quantified the danthonioid climate space as the climatic conditions of all grid cells with at least one danthonioid record (danthonioid grid cells). All grid cells currently occupied by danthonioid species are therefore considered to have climatic conditions suitable for danthonioid species. We compared the climate of each grid cell to the climate of all danthonioid grid cells within a region and considered the climate of two grid cells to be analogous if the difference in all six climate variables was smaller than a given niche breadth threshold. As a sensitivity test we used three niche breadths (see Appendix S1 in Supporting Information), based on the variation around the median of each climate variable after excluding outliers (highest and lowest $10 \%$ of plots for each climate variable), calculated over all four continents. The narrow niche breadth corresponds to the 5th, the medium to the 10th, and the wide to the 25th percentile. A small area value indicates that the climatic conditions of that grid cell are analogous to those of only a few grid cells with danthonioid records (indicating potentially lower climatic suitability for danthonioids);

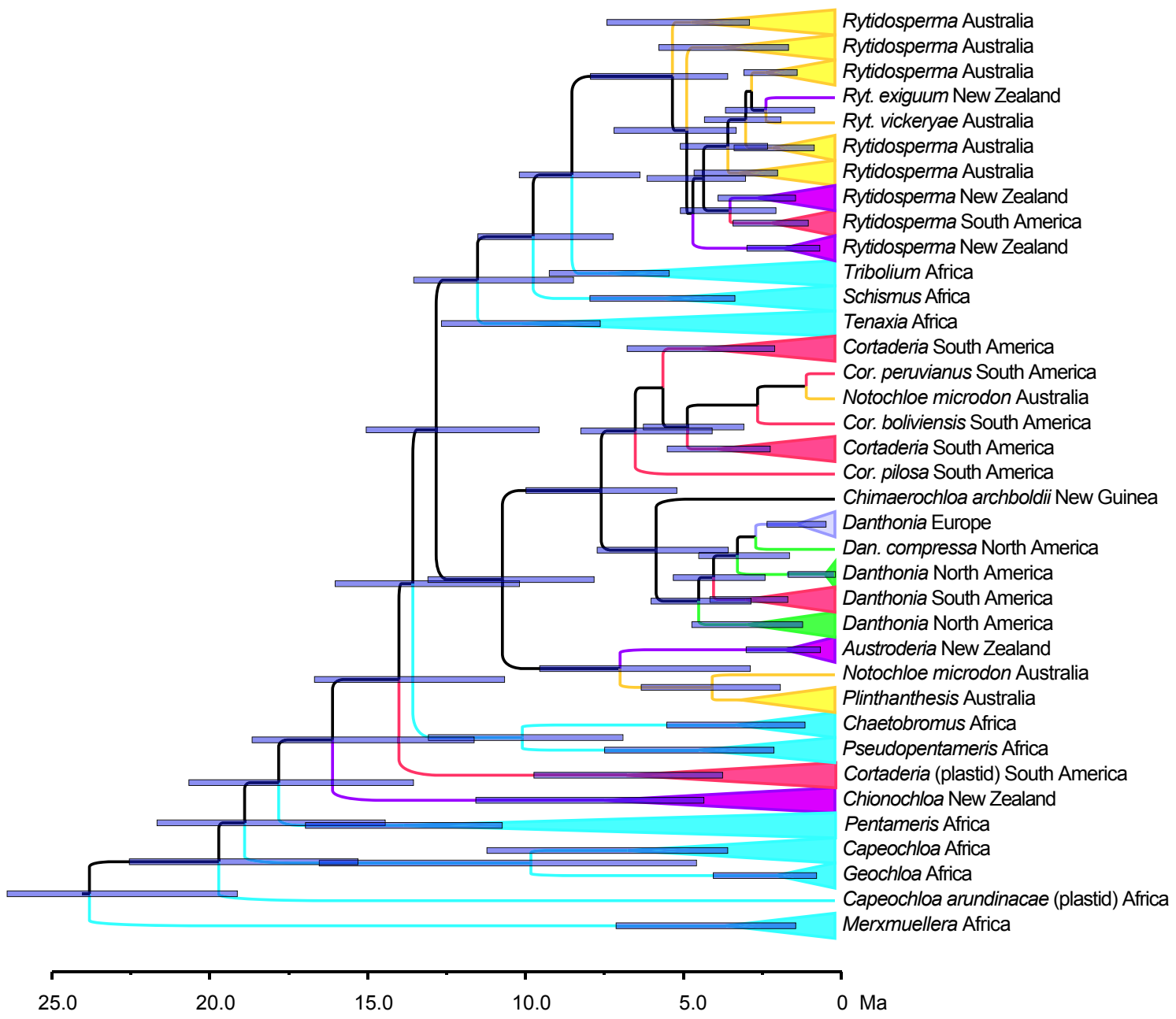

Figure 2 Maximum clade credibility tree of the danthonioids. Species belonging to the same genus and from the same area have been collapsed. Age bars indicate the $95 \%$ highest probability density (HPD) distributions of the BEAST age estimates. The colour coding reflects the regions: blue, Africa; purple, New Zealand; red, South America; yellow, Australia; green, North America; mauve, Europe. 
a high value indicates that the climatic conditions of that grid cell are analogous to those of many grid cells with danthonioid records (indicating potentially higher climatic suitability for danthonioids). The number of species per cell was not taken into account. All grid cells with LGM conditions analogous to current conditions of any of the grid cells with danthonioid records were considered to have had 'danthonioid climate space' at the LGM. We took account of the lowered sea level during the LGM, as quantified by Braconnot et al. (2007).

\section{RESULTS}

\section{Phylogeny}

The phylogeny of the Danthonioideae is well resolved (Fig. 2) and most nodes robustly supported. The only problematic taxon is Danthonia, where the relationships among the North and South American species remain unclear in this and previous analyses. Dating gives relatively wide highest probability densities, but this should not affect our analyses, as we are mostly interested in the relative age of clades and their general timeframe for assessing correspondence with major climatic and geological changes.

\section{Continental radiation patterns}

Models with region-specific, time-varying rates of speciation (RegionalDynamic) dramatically outperformed all other candidate models (Fig. 3). The overall best-fit model was the most complex one considered and included extinction and symmetric dispersal between regions $\left(\mathrm{AIC}_{\mathrm{c}}=1124.6 ; 22\right.$ parameters). However, the corresponding model without extinction (RegionalDynamic plus symmetric dispersal) provided a comparable fit to the data with substantially fewer parameters $\left(\mathrm{AIC}_{\mathrm{c}}=1125.1 ; 14\right.$ parameters $)$. Together, these two models explained $96.2 \%$ of the total probability of the data (Fig. 3b) given the candidate set of models. Regardless of dispersal scenario and extinction model, the RegionalDynamic class of models vastly outperformed all other classes of models. The cumulative conditional probability (Akaike weights) of the six RegionalDynamic models, relative to the other 18 models, exceeds 0.9999 (Table 1, Fig. 3). These results strongly suggest that rates of species diversification vary among geographical regions, and that these rates have varied independently through time.

Lineage-through-time curves reflect a much earlier start for the danthonioid radiation in Africa (22 Ma) relative to other regions (Fig. 4). Under the best fit model, all speciation events prior to 7.0 Ma occurred in Africa, and this is generally true for the other models as well. The first node that can be assigned with confidence to Australia is dated to 5.0 Ma, New Zealand to $6.0 \mathrm{Ma}$ and South America to 6.7 Ma. This suggests a long history of diversification in Africa, with relatively recent 'out of Africa' dispersals to the other regions, and diversification within those regions.

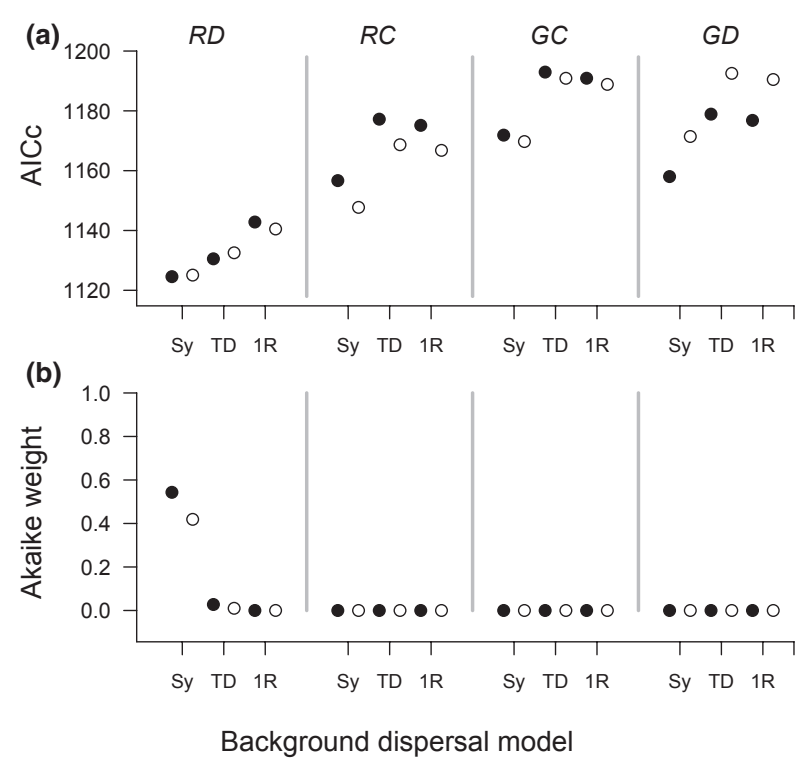

Figure 3 Comparison of performance of the radiation models of the danthonioid grasses based on (a) finite-sample corrected Akaike information criterion $\left(\mathrm{AIC}_{\mathrm{c}}\right)$ scores and (b) Akaike weights, showing the better performance of the most complex models. Background dispersal models: Sy = 'Symmetric', separate but symmetric, time-invariant dispersal among each pair of continents; TD = 'Time Dependent', allowing dispersal rates to vary between regions linearly through time; $1 \mathrm{R}=$ equal rates among the geographical regions. Speciation models: $\mathrm{RD}=$ 'Regional Dynamic', rates allowed to vary through time within regions; $\mathrm{RC}=$ 'Regional Constant', rates constant through time, but each region allowed to have a separate rate; $\mathrm{GC}=$ 'Global Constant', rates of species diversification assumed to be constant; GD = 'Global Dynamic, rates allowed to vary linearly through time, but all regions with common rate parameters. Extinction models: empty dots $=$ extinction rates equal to zero; black dots $=$ extinction rates allowed to vary as mirror to speciation model.

Table 1 Summary of diversification patterns of danthonioid grasses across the four major classes of diversification models. Each class of model was fitted against three background dispersal scenarios, both with and without extinction (eight submodels per model class). Mean $\Delta \mathrm{AIC}_{\mathrm{c}}$ (change in finitesample corrected Akaike information criterion) gives the mean $\Delta \mathrm{AIC}_{\mathrm{c}}$ value for all eight submodels per model class, and summed $\Delta_{i}$ gives the cumulative conditional probability (Akaike weight) for each model class.

\begin{tabular}{lll}
\hline Model & Mean $\Delta \mathrm{AIC}_{\mathrm{c}}$ & Summed $\Delta_{i}$ \\
\hline GlobalConstant & 59.63 & 0 \\
GlobalDynamic & 53.46 & 0 \\
RegionalConstant & 40.80 & 0 \\
RegionalDynamic & 8.11 & 1 \\
\hline
\end{tabular}

Speciation rates in Africa and Australia appear to have decreased through time (Fig. 5, and Fig. S1 in Appendix S2), regardless of whether non-zero extinction is included in the 

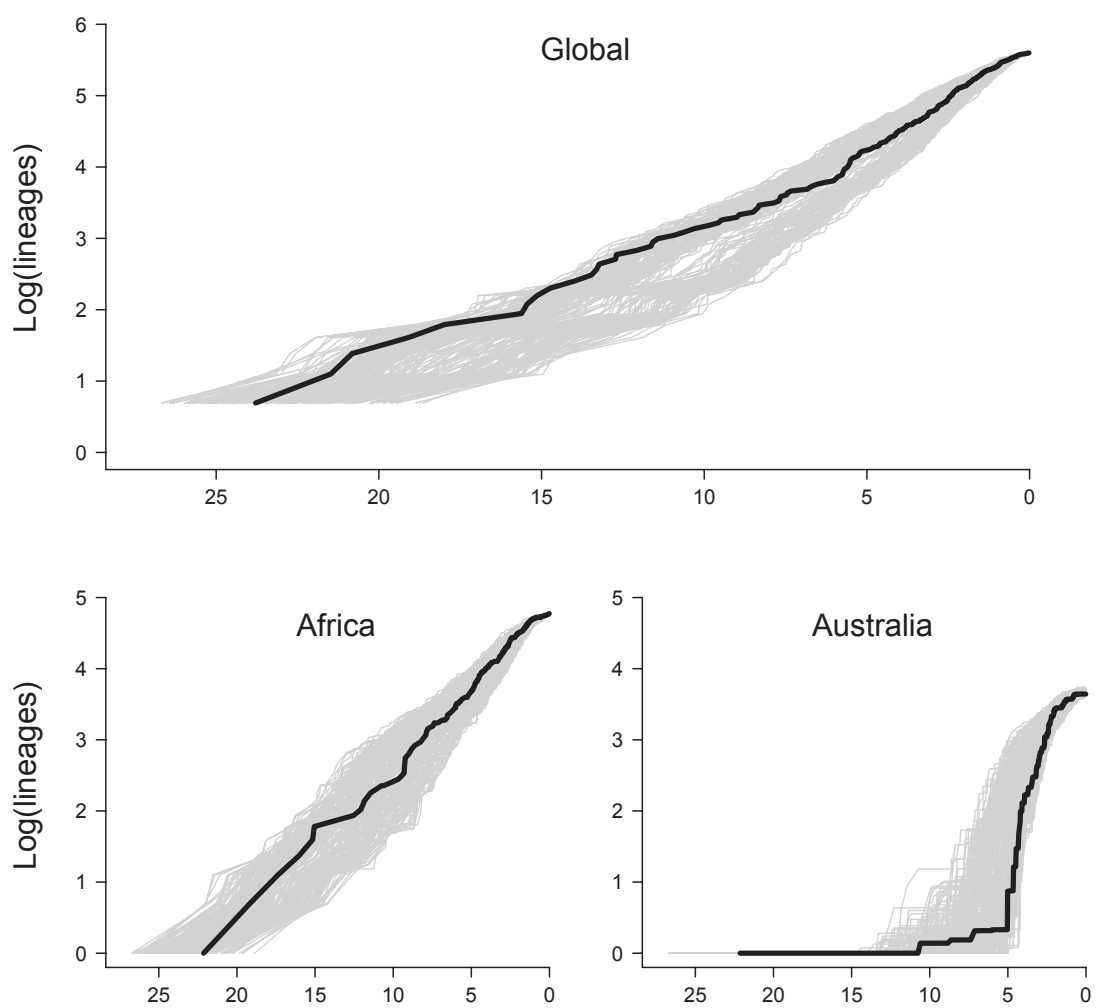

Figure 4 Lineage-through-time plots for the danthonioids, for the global as well as the regional diversities. The slight global acceleration in diversification in the last $5 \mathrm{Myr}$ is the cumulative result of the regional diversifications in Africa, Australia, New Zealand and South America.
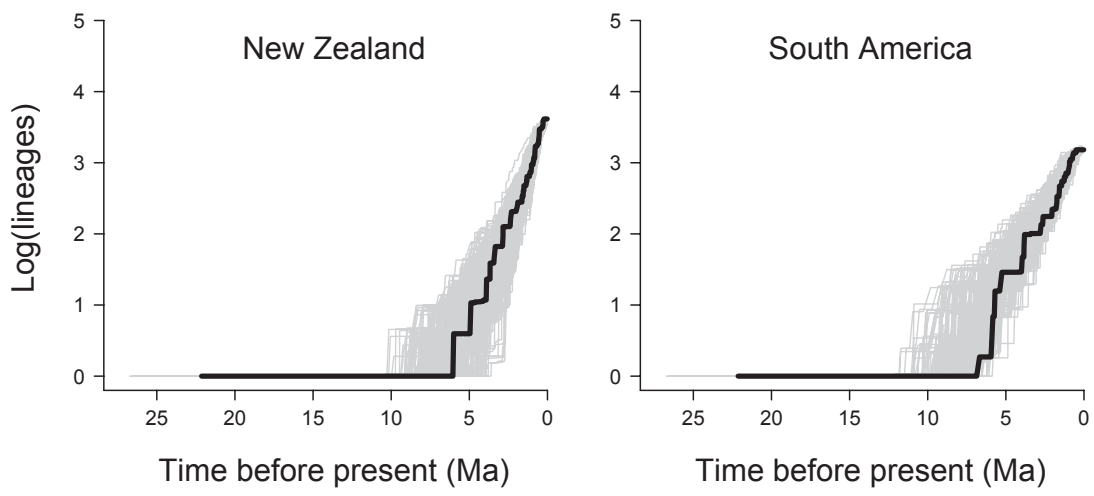

RegionalDynamic model. In contrast, there is no evidence for declining rates in the other austral landmasses. For Africa, the full model with extinction suggests that net diversification rates have been approximately zero through time (Fig. 5, Fig. S1). However, the model with extinction constrained to equal zero (Fig. $5 \mathrm{~b}$ ) provides an equivalent fit to the data (Fig. 3) suggests low but positive net diversification rates. Rates in South America appear to have been stable through time, and extinction rates are substantially lower than speciation rates. Speciation rates in New Zealand have increased strongly towards the present, while extinction rates remained constant.

\section{Available climate space}

Under current climate conditions, the danthonioids in southern Africa, Australia and South America are restricted to the cooler, moister parts of the climate space, mostly below $20{ }^{\circ} \mathrm{C}$ mean annual temperature (Fig. S2 in Appendix S2), consistent with their absence from tropical and arid regions and corroborating their status as grasses of temperate regions. During the LGM most continents are modelled to have had colder and drier climates, and as a result in many regions danthonioid space was spatially shifted and changed in area (Fig. S3 in Appendix S2). However, the results depend on the assumptions made (Table 2). For both CCSM and MIROC with a narrow niche definition, the danthonioid area was a fraction of that currently available. The most extreme was for Australia and New Zealand under the CCSM model, where available habitat was only $20 \%$ of currently available. Under a medium niche breadth assumption the results were mixed: South America lost area under both models; Australia and New Zealand only under the CCSM model, and Africa had more danthonioid habitat under both 
(a) RegionalDynamic, with extinction
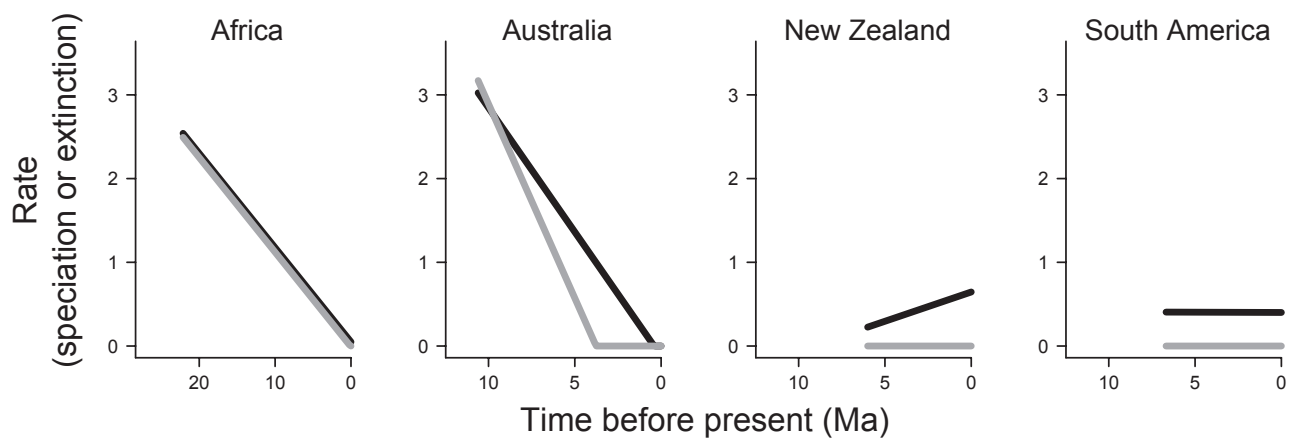

(b) RegionalDynamic, no extinction
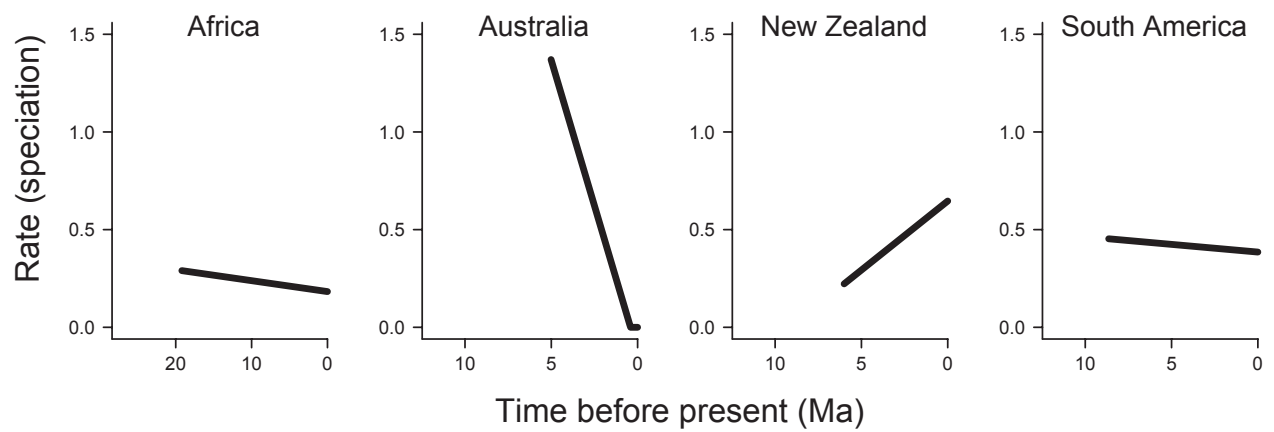

Time before present (Ma)

Figure 5 (a) Speciation (black) and extinction (grey) rates of the danthonioid grasses through time for the RegionalDynamic diversification model fitted to the maximum clade credibility tree with time-varying extinction. (b) Corresponding plot for the RegionalDynamic model with extinction constrained to zero. Models shown in (a) and (b) provided roughly equivalent fits to the data and outperformed all other models in the candidate set. Note that Africa is on a different time-scale than the other three regions. Compare (a) with plots of the net speciation rate through time (speciation - extinction), as shown in Fig. S1 in Appendix S2.

models (Table 2). With the wide niche breadth all continents had more danthonioid habitat area available during the LGM than currently under both models. In both southern Africa and Australia, danthonioid climate space during the LGM was located further north than it currently is. The degree of spatial overlap between the projected suitable climate habitats between current and LGM climates varies between the LGM climate models, and the niche breadth used (Table 2). A general pattern is that the overlap was much smaller in South America, for the same models and niche parameters, than in the other three continents.

\section{DISCUSSION}

We found the strongest overall support for models of diversification with distinct time-varying diversification regimes within each of the four land masses (RegionalDynamic). This allows for changing diversification rates (potentially densitydependent slowdowns), and for different rates among the continents (potentially consistent with the different sizes of the continents and the ages of the danthonioid floras), as well as for an effect of different immigration rates (increasing the disparity). Including extinction in the model led to only marginal improvements in model fit (Fig. 3). Diversification rates have decreased in Australia and increased in New Zealand. For Africa and South America, diversification rates have either declined weakly through time or remained constant, depending on the underlying extinction model (Fig. 5). This rate variation is not explained by continental size or the ages of the danthonioid floras, and is therefore inconsistent with the density-dependent hypothesis. It appears that longdistance dispersal, climate change and orogeny may play a prominent role.

\section{Long-distance dispersal}

The macroevolutionary consequences of long-distance dispersal (LDD) have been little explored. Bacon et al. (2012) suggested that Miocene dispersal might have been an important driver of diversification in palms, and indeed in plants in general. Our results corroborate this, and dispersal rate is part of the best speciation and extinction models, indicating that immigration led to increased diversification. Usually, immigration is treated as an alternative to in situ speciation (Lancaster \& Kay, 2013), especially important in young areas, or in areas too small to support own speciation (Losos \& Schluter, 2000). Our data suggest two mechanisms: the one as trigger for new rounds of diversification, and the second 
Table 2 Proportion of overlap between current modelled and Last Glacial Maximum (LGM) modelled areas of danthonioid grasses. The niche breadths are based on the variation around the median of each climate variable after excluding outliers. The narrow niche breadth corresponds to the 5th, the medium to the 10th, and the wide to the 25th percentile. (a) Proportion of current modelled suitable area that was also modelled as suitable under LGM conditions. (b) Proportion of area modelled suitable at the LGM that was also modelled as suitable currently.

\begin{tabular}{|c|c|c|c|c|}
\hline & \multicolumn{2}{|l|}{ (a) } & \multicolumn{2}{|l|}{ (b) } \\
\hline & $\begin{array}{l}\text { MIROC } \\
(\%)\end{array}$ & $\begin{array}{l}\text { CCSM } \\
(\%)\end{array}$ & $\begin{array}{l}\text { MIROC } \\
(\%)\end{array}$ & $\begin{array}{l}\text { CCSM } \\
(\%)\end{array}$ \\
\hline \multicolumn{5}{|c|}{ Narrow niche breadth } \\
\hline South Africa & 12.5 & 19.2 & 39.8 & 48.5 \\
\hline Australia & 12.3 & 5.8 & 69.3 & 61.4 \\
\hline New Zealand & 5.6 & 3.7 & 22.6 & 19.8 \\
\hline South America & 2.7 & 3.9 & 5.9 & 11.5 \\
\hline \multicolumn{5}{|c|}{ Medium niche breadth } \\
\hline South Africa & 55.0 & 69.8 & 48.3 & 53.7 \\
\hline Australia & 68.7 & 28.0 & 62.4 & 53.2 \\
\hline New Zealand & 59.5 & 39.4 & 48.8 & 50.0 \\
\hline South America & 18.2 & 16.6 & 25.2 & 27.6 \\
\hline \multicolumn{5}{|c|}{ Wide niche breadth } \\
\hline South Africa & 84.2 & 85.7 & 54.7 & 54.2 \\
\hline Australia & 99.6 & 97.6 & 73.2 & 64.1 \\
\hline New Zealand & 98.2 & 91.4 & 52.9 & 54.1 \\
\hline South America & 75.2 & 75.5 & 56.5 & 54.5 \\
\hline
\end{tabular}

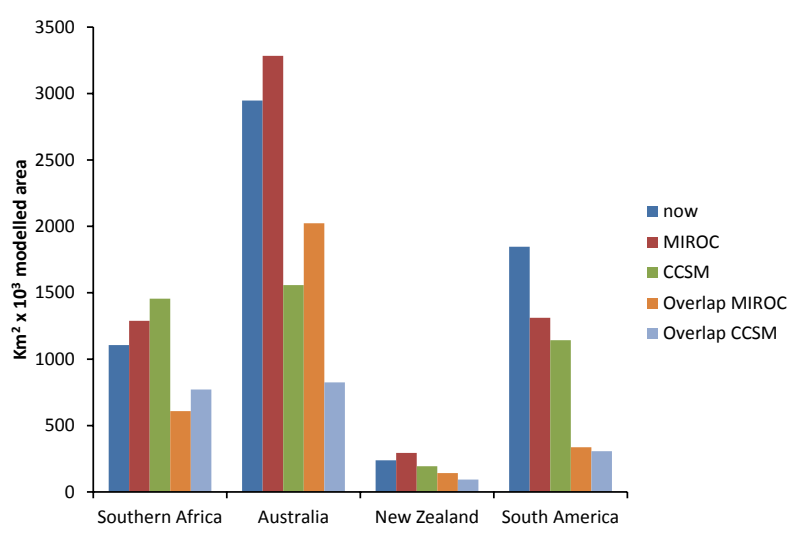

Figure 6 Area with danthonioid climate, under the medium niche breadth in the four regions, under contemporary and Last Glacial Maximum (LGM) climate conditions using two LGM climate models (MIROC, CCSM). Overlap indicates the area with climatic conditions suitable for danthonioids under contemporary and LGM conditions for each of the two LGM climate models. Note the small area of New Zealand, the very small overlapping area in South Africa, and the substantial differences between the two models for Australia.

to bolster current diversification. Both lead to an increase in both global and regional diversification rate. Dispersal from Africa more than doubled the total diversity in the subfamily: in Africa only 138 species are found, the additional 144 species are the result of radiations on new continents follow- ing LDD, in some cases adding radiations to continents where there was already a danthonioid radiation (e.g. the Rytidosperma radiation in New Zealand, where Chionochloa had already been established). Furthermore, immigration might facilitate the generation of novel phenotypes through hybridization, thus stimulating diversification (Wagner et al., 2012). Our phylogenetic analyses indicate incongruence between the phylogenies of nuclear and plastid genomes in the South American Cortaderia, the Australian Notochloe, and the African Capeochloa (Pirie et al., 2009), suggesting that hybridization may have taken place in the Danthonioideae. Some of the radiations could have resulted from hybridization following repeated dispersal. Furthermore, dispersal may have contributed to danthonioid trait diversity on continents. Linder et al. (2013) postulated five dispersal events to New Zealand, which introduced three morphologically and ecologically divergent forms (Chionochloa with tough leaves; Austroderia, a tall fibrous tussock of disturbed habitats; and three Rytidosperma invasions of soft small tufted plants). Currently the three genera occupy somewhat different niches in New Zealand.

\section{Quaternary climatic oscillations}

The Quaternary climatic fluctuations may have impacted the diversification rate through changing the speciation rate, but more likely by modifying the extinction rate. We expect continents with a major difference in suitable area, and its location, between the glacials and interglacials to have had a higher extinction rate. However, we find that the reconstructions are complex, and that the climatic fluctuations may have been modified by the different mountain configurations. In southern Africa, the configuration of the subcontinent relative to the ocean currents may have ameliorated the climatic changes during the Quaternary, with the west coast becoming wetter and the south coast drier during the glacial episodes (Chase \& Meadows, 2007), creating conditions optimal for cool-adapted temperate grasses. This is corroborated by our finding that during the LGM more area was available for the danthonioids (for the medium and wide niche concepts), than currently. Most danthonioid species are either in the Cape Fold Mountains, or along the escarpment, where climatic change can be accommodated by vertical movement.

The dramatic drop in diversification in late Pliocene Australia is puzzling. Our results are ambiguous if we simply test how much area stays within the danthonioid climatic envelope, with MIROC and CCSM giving very different results (Fig. 6, Table 2, Fig. S3). Generally, more area stays suitable for danthonioids in Australia than on other continents, but in the topographically subdued Australian landscapes the same climate changes as on other, more mountainous, continents may result in a much higher climate change velocity (Loarie et al., 2009; Sandel et al., 2011), and as a result species may have to migrate further and faster in order to stay in the same climate envelope species (Corlett \& Westcott, 2013). Indeed, Hill et al. (1999) suggested that the subdued 
Australian terrain meant that species had to migrate long distances to stay in their preferred habitats, thus filtering non-vagile species. This is corroborated by the fossil documentation of a rich sclerophyll flora from the south-east Australian early Pleistocene (Sniderman et al., 2013), an area now poor in sclerophylls.

The high topographic diversity of New Zealand, and the very long coastline, may have had two impacts. Although the Pleistocene glaciations removed some of the habitat of the danthonioids at high elevations, they probably made more of the rest of the island suitable for these grasses. During the glacials extensive closed forest was probably restricted to the northern tip of the archipelago with only small stands and forest microrefugia found in the southern half of the North Island and the northern half of the South Island, opening up extensive areas suitable for cold-adapted grasslands between the ice-cap and the forests (Newnham et al., 2013). Furthermore, the LGM land area of New Zealand was almost twice as large as it is today. These suitable habitats were geographically close to the current habitats (contrary to the situation in Australia), thus not requiring long-distance migration.

Diversification of the South American danthonioids shows long-term diversification stability. The clade ranges over the whole elevational range, and from the Atlantic to the Pacific coast, but the greatest diversity is found in the Andes. It is possible that Pleistocene climatic fluctuations could have been accommodated with vertical migration, but at our $2.5^{\prime}$ resolution, very few cells remain within the danthonioid climatic envelope during the whole of the Quaternary, and the extent of danthonioid habitat may have been underestimated (Randin et al., 2009).

\section{Neogene orogeny and speciation}

Recent orogeny is linked to accelerated diversification. The most recent orogeny in the danthonioid distribution range was in New Zealand (Table 3), where alpine conditions were established only in the Pleistocene (Heenan \& McGlone, 2013), and this region had the most rapid recent acceleration of diversification. The diversification of several plant groups including Dracophyllum (Ericaceae) (Wagstaff et al., 2010), Ourisia (Plantaginaceae) (Meudt et al., 2009) and the hebes (Veronica,
Plantaginaceae) (Wagstaff et al., 2002) have been linked to this orogeny. The South American Andes may have reached their current elevations and climates by the Late Miocene-Pliocene transition (Bershaw et al., 2010), thus substantially earlier than the New Zealand Alps. Consistent with this, the South American danthonioid diversification has been constant, with a positive rate where speciation exceeds extinction. Next in age and stability could be ranked southern Africa, where the current configuration of mountains dates, as in Australia, to the Cretaceous sundering of Gondwana, but with an Early Miocene as well as a Pliocene uplift rejuvenating the mountains and so erosion (Table 3). Diversification is modelled to be at a constant rate but with decreasing speciation and extinction rates. The Pliocene uplift along the eastern seaboard has been proposed as an important contributor to the diversification of Melianthus (Linder et al., 2006) and possibly an important contributor to the diversification of the Cape flora (Cowling et al., 2009). The geologically most stable area (at least since the Late Miocene) has been Australia, with its rapidly decreasing diversification rate.

This interpretation suggests that the creation of new habitats during orogeny may have stimulated speciation in South America and especially in New Zealand, and that this enhanced speciation rate could have more than counteracted the increased extinction resulting from the climatic fluctuations.

\section{CONCLUSIONS}

The continental-specific differences in danthonioid diversification rates are best explained by topographical differences among the continents. It is striking that the two most geologically dynamic continents - South America and New Zealand - both exhibit no extinction and almost constant or increasing speciation rates (Fig. 5). In contrast, the much more geologically stable African and Australian landmasses exhibit both considerable extinction rates and decreasing speciation rates. We suggest that geologically active areas may have kept producing species and counteracting extinction, as orogenies create new habitats into which radiations can take place. Our reconstructions further suggest that topographical heterogeneity may reduce extinction rates, probably by requiring less horizontal displacement during

Table 3 Summary of the Neogene orogenies in the southern continents.

\begin{tabular}{|c|c|c|c|c|}
\hline Continent & New Zealand & South America & South Africa & Australia \\
\hline Orogeny & Alps & Andes & Fold \& scarp & Alps \\
\hline Early Miocene & Start & Start & $\begin{array}{l}\text { Mountains in place, rejuvenated by } \\
\text { uplift of } c .500 \mathrm{~m} \text { of existing hills }\end{array}$ & $\begin{array}{l}\text { Mountains largely in place. } \\
\text { Gradual uplift in south. }\end{array}$ \\
\hline $\begin{array}{l}\text { Middle Miocene } \\
\text { Late Miocene }\end{array}$ & Hilly? & $\begin{array}{l}\text { Montane, reaching } 2 \mathrm{~km} \\
\text { Alpine, }>4 \mathrm{~km}\end{array}$ & Partial peneplanations & Gradual uplift in south-east. \\
\hline Pliocene & Montane & Alpine, uplift matching erosion & Uplift c. $1000 \mathrm{~m}$ in east & \\
\hline Pleistocene & Alpine & Alpine & Current conditions & \\
\hline Sources & $\begin{array}{l}\text { Heenan \& } \\
\text { McGlone } \\
(2013)\end{array}$ & $\begin{array}{l}\text { Gregory-Wodzicki (2000), Hoorn } \\
\text { et al. (2010), Sepulchre et al. (2010) }\end{array}$ & Partridge \& Maud (2000) & Holdgate et al. (2008) \\
\hline
\end{tabular}


climatic changes. This explanation is consistent for all continents, with low extinction rates for continents containing mountains and high extinction for Australia, which contains least topographic heterogeneity. Possibly diversification rates are generally high in geomorphologically active regions.

\section{ACKNOWLEDGEMENTS}

We thank Matt McGlone for providing background information on the New Zealand environments during the Last Glacial Maximum, Colin Hughes for discussions on the patterns of plant radiations, and numerous herbaria for making their collections and databases available. H.P.L., R.O.W. and A.A. acknowledge funding from the Swiss National Science Foundation grant 31003A-107927 to H.P.L.

\section{REFERENCES}

Alroy, J. (2008) Dynamics of origination and extinction in the marine fossil record. Proceedings of the National Academy of Sciences USA, 105, 11536-11542.

Antonelli, A., Nylander, J.A.A., Persson, C. \& Sanmartín, I. (2009) Tracing the impact of the Andean uplift on Neotropical plant evolution. Proceedings of the National Academy of Sciences USA, 106, 9749-9754.

Antonelli, A., Humphreys, A.M., Lee, W.G. \& Linder, H.P. (2011) Absence of mammals and the evolution of New Zealand grasses. Proceedings of the Royal Society B: Biological Sciences, 278, 695-701.

Bacon, C.D., Baker, W.J. \& Simmons, M.P. (2012) Miocene dispersal drives island radiations in the palm tribe Trachycarpeae (Arecaceae). Systematic Biology, 61, 426-442.

Baldwin, B.G. \& Wagner, W.L. (2010) Hawaiian angiosperm radiations of North American origin. Annals of Botany, 105, 849-879.

Bershaw, J., Garzione, C.N., Higgins, P., MacFadden, B.J., Anaya, F. \& Alvarenga, H. (2010) Spatial-temporal changes in Andean plateau climate and elevation from stable isotopes of mammal teeth. Earth and Planetary Science Letters, 289, 530-538.

Braconnot, P., Otto-Bliesner, B., Harrison, S. et al. (2007) Results of PMIP2 coupled simulations of the Mid-Holocene and Last Glacial Maximum - Part 1: experiments and large-scale features. Climate of the Past, 3, 261-277.

Chase, B.M. \& Meadows, M.E. (2007) Late Quaternary dynamics of southern Africa's winter rainfall zone. EarthScience Reviews, 84, 103-138.

Corlett, R.T. \& Westcott, D.A. (2013) Will plant movements keep up with climate change? Trends in Ecology and Evolution, 28, 482-488.

Cowling, R.M., Rundel, P.W., Lamont, B.B., Arroyo, M.K. \& Arianoutsou, M. (1996) Plant diversity in mediterranean-climate regions. Trends in Ecology and Evolution, 11, 362-366.

Cowling, R.M., Procheş, Ş. \& Partridge, T.C. (2009) Explaining the uniqueness of the Cape flora: incorporating geomorphic evolution as a factor for explaining its diversification. Molecular Phylogenetics and Evolution, 51, 64-74.

Crisp, M.D. \& Cook, L.G. (2009) Explosive radiation or cryptic mass extinction? Interpreting signatures in molecular phylogenies. Evolution, 63, 2257-2265.

Drummond, A.J., Ho, S.Y.W., Phillips, M.J. \& Rambaut, A. (2006) Relaxed phylogenetics and dating with confidence. PloS Biology, 4, 699-710.

Dupont, L.M., Linder, H.P., Rommerskirchen, F. \& Schefuss, E. (2011) Climate-driven rampant speciation of the Cape flora. Journal of Biogeography, 38, 1059-1068.

Etienne, R.S., Haegeman, B., Stadler, T., Aze, T., Pearson, P.N., Purvis, A. \& Phillimore, A.B. (2012) Diversity-dependence brings molecular phylogenies closer to agreement with the fossil record. Proceedings of the Royal Society B: Biological Sciences, 279, 1300-1309.

FitzJohn, R.G., Maddison, W.P. \& Otto, S.P. (2009) Estimating trait-dependent speciation and extinction rates from incompletely resolved phylogenies. Systematic Biology, 58, 595-611.

Galley, C. \& Linder, H.P. (2006) Geographical affinities of the Cape flora, South Africa. Journal of Biogeography, 33, 236-250.

Givnish, T.J., Millam, K.C., Mast, A.R., Paterson, T.B., Theim, T.J., Hipp, A.L., Henss, J.M., Smith, J.F., Wood, K.R. \& Sytsma, K.J. (2009) Origin, adaptive radiation and diversification of the Hawaiian lobeliads (Asterales: Campanulaceae). Proceedings of the Royal Society B: Biological Sciences, 276, 407-416.

Goldberg, E.E., Lancaster, L.T. \& Ree, R.H. (2011) Phylogenetic inference of reciprocal effects between geographic range evolution and diversification. Systematic Biology, 60, 451-465.

Gregory-Wodzicki, K.M. (2000) Uplift history of the Central and Northern Andes: a review. Geological Society of America Bulletin, 112, 1091-1105.

Heenan, P.B. \& McGlone, M.S. (2013) Evolution of New Zealand alpine and open-habitat plant species during the late Cenozoic. New Zealand Journal of Ecology, 37, 105-113.

Hijmans, R.J., Cameron, S.E., Parra, J.L., Jones, P.G. \& Jarvis, A. (2005) Very high resolution interpolated climate surfaces for global land areas. International Journal of Climatology, 25, 1965-1978.

Hill, R.S., Truswell, E.M., McLoughlin, S. \& Dettmann, M.E. (1999) Evolution of the Australian flora: fossil evidence. Flora of Australia, Vol. 43 (ed. by A.E. Orchard), pp. 251320. ABRS/CSIRO, Melbourne.

Hodges, S.A. \& Arnold, M.L. (1995) Spurring plant diversification: are floral nectar spurs a key innovation? Proceedings of the Royal Society B: Biological Sciences, 262, 343348.

Holdgate, G.R., Wallace, M.W., Gallagher, S.J., Wagstaff, B.E. \& Moore, D. (2008) No mountains to snow on: major post-Eocene uplift of the East Victoria Highlands; evidence from Cenozoic deposits. Australian Journal of Earth Sciences, 55, 1184-1187. 
Hoorn, C., Wesselingh, F.P., ter Steege, H., Bermudez, M.A., Mora, A., Sevink, J., Sanmartín, I., Sanchez-Meseguer, A., Anderson, C.L., Figueiredo, J.P., Jaramillo, C., Riff, D., Negri, F.R., Hooghiemstra, H., Lundberg, J., Stadler, T., Särkinen, T. \& Antonelli, A. (2010) Amazonia through time: Andean uplift, climate change, landscape evolution, and biodiversity. Science, 330, 927-931.

Hughes, C. \& Eastwood, R. (2006) Island radiation on a continental scale: exceptional rates of plant diversification after uplift of the Andes. Proceedings of the National Academy of Sciences USA, 103, 10334-10339.

Juan, C., Emerson, B.C., Oromí, P. \& Hewitt, G.M. (2000) Colonization and diversification: towards a phylogeographic synthesis for the Canary Islands. Trends in Evolution and Ecology, 15, 104-109.

Karl, R. \& Koch, M.A. (2013) A world-wide perspective on crucifer speciation and evolution: phylogenetics, biogeography and trait evolution in tribe Arabideae. Annals of Botany, 112, 983-1001.

Kier, G., Kreft, H., Lee, T.M., Jetz, W., Ibisch, P.L., Nowicki, C., Mutke, J. \& Barthlott, W. (2009) A global assessment of endemism and species richness across island and mainland regions. Proceedings of the National Academy of Sciences USA, 106, 9322-9327.

Lancaster, L.T. \& Kay, K.M. (2013) Origin and diversification of the California flora: re-examining classic hypotheses with molecular phylogenies. Evolution, 67, 1041-1054.

Li, L., Li, Q., Tian, J., Wang, P., Wang, H. \& Liu, Z. (2011) A 4-Ma record of thermal evolution in the tropical western Pacific and its implications on climate change. Earth and Planetary Science Letters, 309, 10-20.

Linder, H.P. (2003) The radiation of the Cape flora, southern Africa. Biological Reviews, 78, 597-638.

Linder, H.P. \& Barker, N.P. (2000) Biogeography of the Danthonieae. Grass Systematics and Evolution - Vol. 2 of Proceedings of the Second International Conference on the Comparative Biology of the Monocots, Sydney, September 1998 (ed. by S.W.L. Jacobs and J. Everett), pp. 231-238. CSIRO, Melbourne.

Linder, H.P., Eldenäs, P. \& Briggs, B.G. (2003) Contrasting patterns of radiation in African and Australian Restionaceae. Evolution, 57, 2688-2702.

Linder, H.P., Dlamini, T., Henning, J. \& Verboom, G.A. (2006) The evolutionary history of Melianthus (Melianthaceae). American Journal of Botany, 93, 1052-1064.

Linder, H.P., Baeza P., C.M., Barker, N.P., Galley, C., Humphreys, A.M., Lloyd, K.M., Orlovich, D.A., Pirie, M.D., Simon, B.K., Walsh, N.G. \& Verboom, G.A. (2010) A generic classification of the Danthonioideae (Poaceae). Annals of the Missouri Botanical Garden, 97, 306-364.

Linder, H.P., Bykova, O., Dyke, J., Etienne, R.S., Hickler, T., Kühn, I., Marion, G., Ohlemüller, R., Schymanski, S.J. \& Singer, A. (2012) Biotic modifiers, environmental modulation and species distribution models. Journal of Biogeography, 39, 2179-2190.
Linder, H.P., Antonelli, A., Humphreys, A.M., Pirie, M.D. \& Wüest, R.O. (2013) What determines biogeographical ranges? Historical wanderings and ecological constraints in the danthonioid grasses. Journal of Biogeography, 40, 821-834.

Loarie, S.R., Carter, B.E., Hayhoe, K., McMahon, S., Moe, R., Knight, C.A. \& Ackerly, D.D. (2008) Climate change and the future of California's endemic flora. PLoS ONE, 3, e2502.

Loarie, S.R., Duffy, P.B., Hamilton, H., Asner, G.P., Field, C.B. \& Ackerly, D.D. (2009) The velocity of climate change. Nature, 462, 1052-1055.

Losos, J.B. \& Schluter, D. (2000) Analysis of an evolutionary species-area relationship. Nature, 408, 847-850.

Maddison, W.P., Midford, P.E. \& Otto, S.P. (2007) Estimating a binary character's effect on speciation and extinction. Systematic Biology, 56, 701-710.

Mahler, D.L., Revell, L.J., Glor, R.E. \& Losos, J.B. (2010) Ecological opportunity and the rate of morphological evolution in the diversification of Greater Antilles anoles. Evolution, 64, 2731-2745.

Meudt, H.M., Lockhart, P.J. \& Bryant, D. (2009) Species delimitation and phylogeny of a New Zealand plant species radiation. BMC Evolutionary Biology, 9, 111.

Nee, S., Holmes, E.C., May, R.M. \& Harvey, P.H. (1994) Extinction rates can be estimated from molecular phylogenies. Philosophical Transactions of the Royal Society B: Biological Sciences, 344, 77-82.

Newnham, R., McGlone, M., Moar, N., Wilmshurst, J. \& Vandergoes, M. (2013) The vegetation cover of New Zealand at the Last Glacial Maximum. Quaternary Science Reviews, 74, 202-214.

Pahnke, K., Zahn, R., Elderfield, H. \& Schulz, M. (2003) 340,000-year centennial-scale marine record of Southern Hemisphere climatic oscillation. Science, 301, 948-952.

Partridge, T.C. \& Maud, R.R. (2000) Macro-scale geomorphic evolution of southern Africa. The Cenozoic of southern Africa (ed. by T.C. Partridge and R.R. Maud), pp. 3-18. Oxford University Press, Oxford, UK.

Phillimore, A.B. \& Price, T.D. (2008) Density-dependent cladogenesis in birds. PLoS Biology, 6, 483-489.

Pirie, M.D., Humphreys, A.M., Barker, N.P. \& Linder, H.P. (2009) Reticulation, data combination, and inferring evolutionary history: an example from Danthonioideae (Poaceae). Systematic Biology, 58, 612-628.

Quental, T.B. \& Marshall, C.R. (2011) The molecular phylogenetic signature of clades in decline. PLoS ONE, 6, e25780.

Rabosky, D.L. (2009a) Ecological limits on clade diversification in higher taxa. The American Naturalist, 173, 662-674.

Rabosky, D.L. (2009b) Ecological limits and diversification rate: alternative paradigms to explain the variation in species richness among clades and regions. Ecology Letters, 12, 735-743.

Rabosky, D.L. (2010) Extinction rates should not be estimated from molecular phylogenies. Evolution, 64, 18161824. 
Rabosky, D.L. \& Glor, R.E. (2010) Equilibrium speciation dynamics in a model adaptive radiation of island lizards. Proceedings of the National Academy of Sciences USA, 107, 22178-22183.

Rabosky, D.L. \& Lovette, I.J. (2008a) Density-dependent diversification in North American wood warblers. Proceedings of the Royal Society B: Biological Sciences, 275, 23632371.

Rabosky, D.L. \& Lovette, I.J. (2008b) Explosive evolutionary radiations: decreasing speciation or increasing extinction through time? Evolution, 62, 1866-1875.

Randin, C.F., Engler, R., Normand, S., Zappa, M., Zimmerman, N.E., Pearman, P.B., Vittoz, P., Thuiller, W. \& Guisan, A. (2009) Climate change and plant distribution: local models predict high-elevation persistence. Global Change Biology, 15, 1557-1569.

Ree, R.H. \& Smith, S.A. (2008) Maximum likelihood inference of geographic range evolution by dispersal, local extinction, and cladogenesis. Systematic Biology, 57, $4-14$.

Sandel, B., Arge, L., Dalsgaard, B., Davies, R.G., Gaston, K.J., Sutherland, W.J. \& Svenning, J.-C. (2011) The influence of late Quaternary climate-change velocity on species endemism. Science, 334, 660-664.

Sepkoski, J.J., Jr (1978) A kinetic model of phanerozoic taxonomic diversity I. Analysis of marine orders. Paleobiology, 4, 223-251.

Sepulchre, P., Sloan, L.C. \& Fluteau, F. (2010) Modelling the response of Amazonian climate to the uplift of the Andean mountain range. Amazonia, landscape and species evolution (ed. by C. Hoorn and F. Wesselingh), pp. 211-222. Blackwell Publishing, Chichester, UK.

Sniderman, J.M.K., Jordan, G.J. \& Cowling, R.M. (2013) Fossil evidence for a hyperdiverse sclerophyll flora under a non-Mediterranean-type climate. Proceedings of the National Academy of Sciences USA, 110, 3423-3428.

Soetaert, K., Petzoldt, T. \& Setzer, R.W. (2011) deSolve: general solvers for initial value problems of ordinary differential equations $(O D E)$, partial differential equations (PDE), differential algebraic equations (DAE), and delay differential equations (DDE). Available at: http://cran.r-project.org/ web/packages/deSolve/index.html (accessed January 2011).

Verboom, G.A., Archibald, J.K., Bakker, F.T., Bellstedt, D.U., Conrad, F., Dreyer, L.L., Forest, F., Galley, C., Goldblatt, P., Henning, J.F., Mummenhoff, K., Linder, H.P., Muasya, A.M., Oberlander, K.C., Savolainen, V., Snijman, D.A., van der Niet, T. \& Nowell, T.L. (2009) Origin and diversification of the Greater Cape flora: ancient species repository, hot-bed of recent radiation, or both? Molecular Phylogenetics and Evolution, 51, 44-53.
Wagner, C.E., Harmon, L.J. \& Seehausen, O. (2012) Ecological opportunity and sexual selection together predict adaptive radiation. Nature, 487, 366-369.

Wagner, W.L. \& Funk, V.A. (eds) (1995) Hawaiian biogeography: evolution of a hotspot archipelago. Smithsonian Institution Press, Washington, DC.

Wagstaff, S.J., Bayly, M.J., Garnock-Jones, P.J. \& Albach, D.C. (2002) Classification, origin, and diversification of the New Zealand hebes (Scrophulariaceae). Annals of the Missouri Botanical Garden, 89, 38-63.

Wagstaff, S.J., Dawson, M.I., Venter, S., Munzinger, J., Crayn, D.M., Steane, D.A. \& Lemson, K.L. (2010) Origin, diversification, and classification of the Australasian genus Dracophyllum (Richeeae, Ericaceae). Annals of the Missouri Botanical Garden, 97, 235-258.

Wiens, J.J., Graham, C.H., Moen, D.S., Smith, S.A. \& Reeder, T.W. (2006) Evolutionary and ecological causes of the latitudinal diversity gradient in hylid frogs: treefrog trees unearth the roots of high tropical diversity. The American Naturalist, 168, 579-596.

Wiens, J.J., Sukumaran, J., Pyron, R.A. \& Brown, R.M. (2009) Evolutionary and biogeographic origins of high tropical diversity in Old World frogs (Ranidae). Evolution, 63, 1217-1231.

Winkworth, R.C., Wagstaff, S.J., Glenny, D. \& Lockhart, P.J. (2005) Evolution of the New Zealand mountain flora: origins, diversification and dispersal. Organisms Diversity \& Evolution, 5, 237-247.

\section{SUPPORTING INFORMATION}

Additional Supporting Information may be found in the online version of this article:

Appendix S1 Niche breadth thresholds for each of the six climate variables.

Appendix S2 Supplementary figures (Figs S1-S3).

\section{BIOSKETCH}

Peter Linder is interested in the evolution of plant diversity, particularly in the Southern Hemisphere.

Author contributions: H.P.L. conceived the project; D.R. built the diversification models, A.A. built the phylogeny, R.O. inferred the LGM and contemporary distribution ranges and R.O.W. the contemporary ranges; H.P.L. led, and all contributed to, the writing of the paper.

Editor: Mark Carine 